\title{
Das injunções institucionais à constituição da autoria: uma via para o trabalho com a leitura e a escrita na escola
}

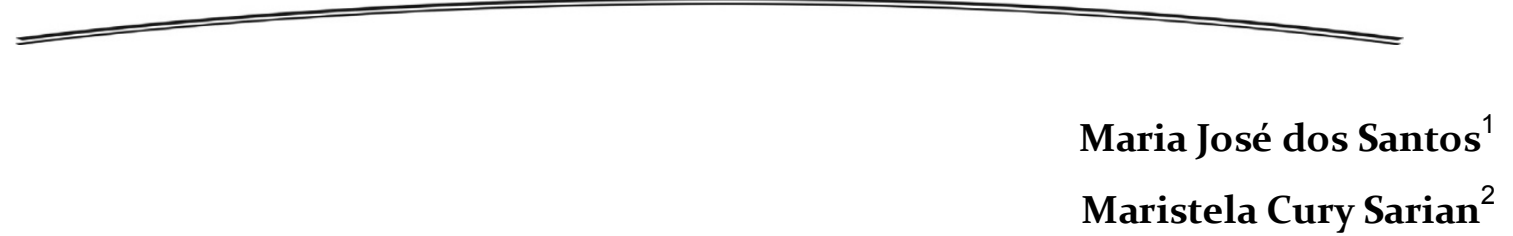

Resumo: Este trabalho tem por objetivo dar visibilidade ao processo de construção de uma proposta de ensino de língua portuguesa, filiada a uma perspectiva discursiva, desenvolvida em uma turma de oitavo ano do Ensino Fundamental de uma escola estadual de Mato Grosso, no ano de 2017, como parte das ações do programa de Mestrado Profissional em Letras (PROFLETRAS) na UNEMAT - Cáceres - MT. Dessa forma, visa a colocar em evidência o modo pelo qual nos autorizamos a criar condições para a instauração de deslocamentos sujeitos e de sentidos nesse espaço tensionado que é a escola, diante das injunções (im)postas pela política educacional do Estado.

Palavras-chave: Análise de discurso. Sala de aula. Prática docente. Gestos de interpretação.

Abstract: The purpose of this work is to give visibility to the process of construction of a Brazilian Portuguese language teaching proposal aligned with a discursive perspective developed with eighth-graders of an Elementary School in the State of Mato Grosso in 2017 as part of the actions of the Professional Master's Program in Languages (PROFLETRAS) at Mato Grosso State University (UNEMAT) in Cáceres. Therefore, the goal is to evidence the way we allow ourselves to create conditions for set up shifts in subjects and meanings within this tensioned space which is the school, before the injunctions (im)posed by the State's educational policy.

Keywords: Discourse analysis. Classroom. Teaching practice. Interpretation gestures.

Resumen: Este trabajo tiene el objetivo de contribuir a dar visibilidad al proceso de construcción de una propuesta de enseñanza de lengua portuguesa, asociada a una perspectiva discursiva, desarrollada con un grupo de alumnos de octavo año de la Enseñanza Secundaria de un colegio público del estado de Mato Grosso, en el año de 2017, como parte de las acciones del programa de Maestría Profesional en Filología (PROFLETRAS) en UNEMAT - Cáceres MT. Así, objetiva poner en evidencia el modo por el cual nos permitimos crear condiciones para la instauración de traslados de indivíduos y de sentidos en ese espacio tensionado que es la escuela, frente a las obligaciones (im)puestas por la política educacional del Estado.

\footnotetext{
1 Professora de Língua Portuguesa da educação básica, vinculada à Secretaria de Estado de Educação - SEDUC/MT. Mestre em Letras pela Universidade do Estado de Mato Grosso - UNEMAT. 2 Professora-orientadora do Programa de Mestrado Profissional em Letras PROFLETRAS/UNEMAT/Cáceres. Doutora em Linguística pela Universidade Estadual de Campinas - UNICAMP.
} 
Palabras clave: Análisis de discurso. Aula. Práctica docente. Gestos de interpretación.

\section{Introdução}

O Programa de Mestrado Profissional em Letras - PROFLETRAS é um Mestrado Profissional em rede e objetiva a qualificação de professores de língua portuguesa do Ensino Fundamental em efetivo exercício na rede pública de ensino.

Coordenado, em nível nacional, pela Universidade Federal do Rio Grande do Norte - UFRN, uma das particularidades do Programa está na natureza de sua concepção. Lemos, no artigo 2º da Resolução no 001/2014 - Conselho Gestor, de 23 de abril de 2014, que "a pesquisa deverá ter como tema/foco/objeto de investigação um problema da realidade escolar e/ou da sala de aula do mestrando no que concerne ao ensino e aprendizagem na disciplina de Língua Portuguesa no Ensino Fundamental” (BRASIL, 2014). Para tanto, explicita-se, no artigo 3oㅡ que "a pesquisa deverá [...] ser de natureza interpretativa e/ou interventiva, ou de interpretação da realidade [...]”, a partir da elaboração de uma "proposta para enfrentar o problema", apresentada no inciso VII do artigo 4º, de onde advém o nome "Projeto de Intervenção".

Nesse sentido, objetivamos, neste artigo, colocar em evidência o processo de constituição de uma proposta de ensino e aprendizagem de Língua Portuguesa desenvolvida na Escola Estadual Pio Machado, no município de Acorizal-MT, entre os meses de março a agosto de 2017 , com alunos do 8 o ano do ensino fundamental, por meio da qual se buscou, primeiramente, uma ressignificação do nosso trabalho de docente, como condição necessária para a instalação de um processo outro de ensino a ser oferecido a nossos alunos ${ }^{3}$.

Nessa direção, daremos visibilidade, ao longo deste texto, num processo não necessariamente linear, ao que nos direcionava em nossa prática docente antes de ingressarmos no PROFLETRAS; ao que nos inquietou na busca do recorte temático e

\footnotetext{
${ }^{3} \mathrm{O}$ modo pelo qual se deu o processo de desenvolvimento desta proposta encontra-se em Santos (2018), mais especificamente, no Capítulo III de sua Dissertação. Por uma questão de recorte, sempre necessário, optou-se, neste trabalho, por dar visibilidade às condições de produção que possibilitaram a construção desta pesquisa.
} 
de novas possibilidades de trabalho em sala de aula junto a nossos alunos; ao nosso encontro com a Análise de Discurso, a partir do qual vislumbramos uma possibilidade de deslocamento a ser efetivado em nossa prática de ensino; à proposição do nosso Projeto de Intervenção, filiado a essa perspectiva teórico-metodológica.

\section{Leitura e escrita na escola: sujeitos e sentidos em (des)construção}

Mantínhamos, desde o início da vida profissional, um incômodo com o trabalho com a leitura e a escrita que vínhamos realizando na escola. Alguns questionamentos nos tomavam: como elaborar e desenvolver um trabalho de leitura com o qual a maior parte dos alunos se identificasse? Como tornar a escrita, nas aulas de português, uma prática significativa? Com o ingresso no Profletras, outros questionamentos nos tomaram: como ressignificar o trabalho que realizávamos até aquele momento? Como dar consequência, na prática, a todas essas inquietações, sustentadas em uma determinada teoria, tal como se compreende neste Programa?

A partir do encontro com a Análise de Discurso de Michel Pêcheux e Eni Orlandi, teoria que filiaria o nosso trabalho, começamos, então, a pensar em uma Proposta que, por um lado, ressignificasse o estabilizado, instituído pelas políticas públicas de ensino, e, por outro lado, fosse possível ser desenvolvida na escola, nessas condições de produção, colocando em movimento a formulação de Pfeiffer (2002, p.14): "a transformação se dá na resistência, na construção de um lugar para se dizer na relação com um dizer legitimado, normatizado”.

Queríamos valorizar os gestos de interpretação dos alunos ${ }^{4}$ e dar condições para a manifestação da autoria5. Considerávamos necessário "criar reais espaços

\footnotetext{
${ }^{4}$ Pela perspectiva da Análise de Discurso, a forma sujeito é histórica e, nessa direção, não há correspondência biunívoca obrigatória entre o lugar social e a posição do sujeito (ORLANDI, 2015). Nesta teoria de entremeio, o sujeito é descentrado, da ordem do inconsciente, e "pensado como 'posição' entre outras" (ORLANDI, 2015, p. 47). Desta forma, o sujeito-aluno, enquanto sujeito da escolarização, deve ser compreendido como uma posição institucionalizada no espaço escolar, assim como o professor. Não se trata, portanto, de uma concepção de sujeito da ordem do empírico.

${ }^{5}$ Está se compreendendo autoria no espaço escolar como efeito de um processo que autoriza e legitima a produção de gestos de interpretação de professores e alunos inscritos na repetição histórica (PFEIFFER, 1995). No que diz respeito mais especificamente à posição de sujeito-leitor, ocupada também por professores e alunos, este "tem sua identidade configurada enquanto tal pelo
} 
interpretativos nos quais os alunos se inscrevam no interdiscurso, criando sítios de significância e, portanto, historicizando seus sentidos e colocando-se ativo no funcionamento da linguagem”. (PFEIFFER, 2003, p. 103).

Com esse desejo, a fim de iniciar a elaboração do Projeto a ser desenvolvido com nossos alunos, recorremos, como ponto de partida, ao Projeto Político Pedagógico da Escola Estadual Pio Macho (2017, p. 5, PPP, doravante), a fim de encontrar algumas pistas para ancorar a nossa Proposta. Conforme este instrumento, "as aulas são planejadas de acordo com os Parâmetros Curriculares Nacionais através do livro didático e são complementadas com atividades extras”. O documento é embasado na Lei de Diretrizes e Bases 9394/96 (LDB) e nas Orientações Curriculares (MATO GROSSO, 2010a), doravante, OCs.

Como não encontramos no PPP uma concepção definida de como a leitura e a escrita são compreendidas e, consequentemente, poderiam ser trabalhadas em nossa escola, recorremos às OCs, mais precisamente, ao caderno que se destina às Linguagens, onde se lê: "a leitura é uma atividade de interação entre o leitor e o texto, em que o primeiro atua na atribuição do(s) sentido(s)" (MATO GROSSO, 2010a, p. 44). Compreendemos que o sentido de leitura em funcionamento é o de leitura como responsabilidade exclusiva do leitor no que tange à produção de sentido, desprezando que este processo se realiza "pela interação entre o produtor de textos, o texto (incluindo suas condições de produção) e o leitor". (ROMÃO; PACÍFICO, 2006, p. 27).

Seguindo a leitura deste documento, encontramos: "na atividade de produção escrita o estudante precisa ser ensinado a assumir-se como autor de seus textos". (MATO GROSSO, 2010a, p. 101, grifos do autor). Porém, não há uma especificação sobre como poderia se dar esse processo de ensino-aprendizagem baseado na produção escrita, apenas o relaciona ao trabalho com "textos dos variados gêneros discursivos [...] escritos presentes em nossa sociedade tendo em vista que cada gênero apresenta especificidades diferenciadas". (MATO GROSSO, 2010a, p. 102). Em consequência, a Política de Formação Continuada oferecida aos docentes pelo Estado se baseia nessa legislação e orienta que o trabalho esteja fortemente associado aos gêneros. (ORLANDI, 2015, p. 76). Ao longo deste trabalho, estas noções serão novamente mobilizadas. 
Mesmo com essa periódica formação pela qual vínhamos passando, a produção de leitura e de elaboração de textos de nossos alunos não mostrava resultados significativos e era alvo de um recorrente discurso sobre as dificuldades que os alunos apresentavam em relação à leitura, à interpretação de texto e à escrita na maioria das disciplinas. Por essa razão, desejávamos um trabalho, no Projeto de Intervenção, que acolhesse a leitura e a escrita, porque entendemos que são práticas de linguagem constitutivas de um trabalho com a Língua Portuguesa na escola.

Alguns investimentos nessa direção chegaram a ser dados pelo corpo docente da escola. No ano de 2015, a leitura foi um dos quatro eixos trabalhados durante o ano letivo na Sala de Educador, que era o modelo de formação continuada, instituído pela Secretaria de Estado da Educação, realizado na escola, com a supervisão da Coordenação Pedagógica. Naquele momento, tinha-se certa autonomia na escolha dos estudos que seriam realizados ao longo de cada ano, de acordo com as necessidades dos discentes. Porém, em 2016, houve uma alteração no projeto de formação continuada na política do Estado de Mato Grosso e o corpo docente da escola dedicou o ano aos estudos do novo modelo de formação, que passou a se chamar Projeto de Estudos e Intervenção Pedagógica (PEIP, doravante), “instrumento de planejamento das ações de formação e desenvolvimento profissional nas escolas da rede pública estadual de ensino de Mato Grosso", institucionalizado pela Portaria no 161/2016/GS/SEDUC/MT.

O parágrafo $2^{\circ}$ do artigo $3^{\circ}$ caracteriza o PEIP, ao estabelecer que

\begin{abstract}
os estudos, as pesquisas e os projetos de intervenção pedagógica deverão ter foco na análise de necessidades de aprendizagem dos estudantes, para superar as dificuldades diagnosticadas ou potencializar a aprendizagem discente, permitindo, por outro lado, a aprendizagem profissional docente (MATO GROSSO, 2016, p. 40).
\end{abstract}

Esses estudos continuaram até meados de 2017 e ficou estabelecido que, a partir desse momento, começaríamos a implantação do Projeto de Intervenção, porque a "meta" e a "ordem" da vez era aumentar o desempenho nos avaliadores externos, como Prova Brasil e IDEB ${ }^{6}$.

\footnotetext{
${ }^{6}$ Nos anos de 2009 e 2011, os resultados foram 4,0 e 4,3, ao passo que os da média projetada eram 3,6 e 3,9, respectivamente. Porém, em 2013 e 2015, além de não alcançarmos a média projetada,
} 
O Profletras também propõe o desenvolvimento de um projeto de natureza intervencionista, daí o nome Projeto de Intervenção, embora a concepção de intervenção dada a este Programa, na Unidade da Unemat/Cáceres, tenha como objetivo "mostrar o deslocamento, a inovação, a transformação de uma prática até então realizada em sala de aula, com base na filiação a uma determinada perspectiva

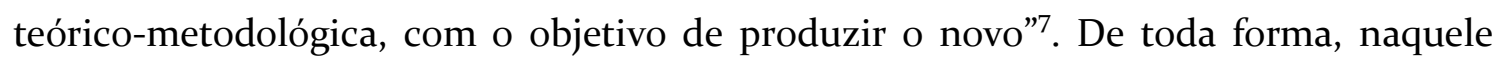
momento de elaboração do Projeto, víamos uma relação de aproximação entre o Projeto de Intervenção proposto pelo Profletras e o trabalho que a Secretaria de Estado da Educação de Mato Grosso visava a implantar nas escolas da rede estadual de todo o Estado que atendiam o Ensino Fundamental.

Antes mesmo da implementação desse Projeto de Intervenção pelo Governo de Mato Grosso, a gestão e o corpo docente da escola já se preocupavam com a questão das avaliações institucionais, como o Índice de Desenvolvimento da Educação Básica (IDEB). No entanto, com nossa entrada na Análise de Discurso, passamos a compreender que alcançar a média projetada para o ano de 2017 ou até mesmo obter alguns avanços em relação ao resultado obtido na última avaliação não seria possível se não houvesse algum tipo de mudança nas concepções que sustentam as práticas de linguagem escolares. Dessa forma, compreendemos que se fazia necessário nos perguntarmos sobre os sentidos de ensino de língua em funcionamento nessas avaliações, de modo a problematizá-las, na relação com as propostas de ensino praticadas nas escolas.

Se, inicialmente, víamos uma aproximação, a partir de então observamos um distanciamento em termos de concepção entre o Projeto de Intervenção proposto pelo Profletras e o Projeto de Intervenção proposto pelo Estado, pois a formação continuada institucionalizada na escola nos direcionou para um projeto específico que buscava desenvolver um trabalho que proporcionasse aos alunos um maior desempenho com

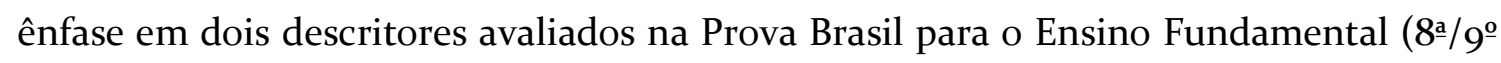

que era 4,3 e 4,7, também estagnamos nos resultados observados, que foram 4,1 nesses dois anos. Em 2015, a escola ficou com a média 4,1, ao passo que a cidade ficou com 4,2 na rede estadual de ensino, e o Estado de Mato Grosso alcançou 4,5 nos anos finais do Ensino Fundamental.

${ }^{7}$ Orientação presente nas Considerações sobre a Elaboração do Projeto de Intervenção, documento elaborado pelos docentes do PROFLETRAS - UNEMAT - Cáceres - MT para esta unidade. 
EF): o D1 (localizar informações explícitas em um texto) e o D4 (inferir uma informação implícita em um texto).

Com base nos descritores da Prova Brasil, avaliamos bimestralmente, na escola, os objetivos de aprendizagem. Vemos, no primeiro objetivo, que a avaliação considera se o aluno "interpreta a intencionalidade do autor na leitura de diferentes textos, identificando informações explícitas e implícitas". A leitura é reduzida ao campo de uma suposta intencionalidade e ainda se espera que o aluno identifique informações explícitas e implícitas "presentes" no texto. Nessa compreensão, "o aluno é apenas um observador da linguagem, não lhe cabe interferir nela, ele só deve organizá-la de acordo com uma organização a priori externa a ele” (PFEIFFER, 2003, p. 97, grifos da autora), pois “é cobrado que ele apenas reconheça no texto certo tipo de informação". (PFEIFFER, 2003, p. 97).

Em relação à produção de sentidos, compreendemos que "os sentidos são no meio de outros e há mais espaço para incertezas do que para afirmações categóricas quando se trata de pensar os sentidos, no modo como eles funcionam pela ideologia em um mundo a significar" (ORLANDI, 2004, p. 128). Porém, "quando na escola se fala sobre o sentido do texto se está ocultando o fato de que há sentidos estabelecidos para ele" (ORLANDI, 2011, p. 213, grifos da autora). E, neste caso específico, é requerido o sentido produzido pelo autor, o que nos causa estranheza, porque compreendemos que não é desta maneira que se dá o processo o qual, para nós, envolve autor, texto, leitor em suas condições de produção.

Já o segundo objetivo "faz uso de concordância verbal e nominal na construção de textos formais", relaciona-se à escrita e aponta um dos conteúdos normalmente trabalhados na escola e em circulação em grande parte do material didático de língua portuguesa, que é a "concordância verbal e nominal". Apontamos a fragmentação dos saberes sobre o ensino da língua a partir de uma visão gramaticista normativa, além de direcionar um objetivo para um único "conteúdo" entre os que se trabalha nas aulas. Na sequência, o mesmo objetivo associa esse uso aos "textos formais", que podemos associar como os inscritos no discurso escrito, como se estas concordâncias fossem feitas apenas nesses textos. O que nos causa estranheza é o objetivo direcionar a avaliação para apenas um dos componentes que envolvem a produção/construção de 
textos, silenciando outros elementos do processo que envolve a assunção da autoria (GALLO, 1990).

Ao refletirmos sobre a proposta de Projeto de Intervenção implantado pelo Governo de MT, observamos o funcionamento de três reducionismos referentes à leitura indicados por Orlandi (2012a, p. 46), que são: “o pedagogismo”, que "é acreditar em soluções pedagógicas desvinculando-as do seu caráter sócio-histórico”; “o da classe média", em que "a escola, tal como existe [...] propõe de forma homogênea que todo mundo leia como a classe média lê" (ORLANDI, 2012a, p. 48), e "o reducionismo linguístico", em que "se poderia tomar a leitura como decodificação e se proporiam técnicas que derivassem do conhecimento linguístico estrito" (ORLANDI, 2012a, p. 4849).

Vemos o pedagogismo em funcionamento quando o Estado impõe soluções pedagógicas como os objetivos de aprendizagem e espera resultados imediatistas; o reducionismo da classe média está caracterizado na própria natureza da Prova Brasil, que homogeneíza a leitura dos alunos, fazendo circular o saber dominante (mas questionado) sobre língua, interditando a produção de sentidos, visto que já são postos; e o reducionismo linguístico filia-se à concepção de leitura de conteúdo, em que o texto teria um sentido único e o aluno deve apreendê-lo em questões de múltipla escolha.

Ao se trabalhar a leitura pelo viés da $\mathrm{AD}$, entendemos que "a linguagem não é transparente. Desse modo, ela não procura atravessar o texto para encontrar um sentido do outro lado" (ORLANDI, 2015, p.15-16). Assim sendo, precisa haver um deslocamento na maneira como a leitura e a interpretação vêm sendo trabalhadas na escola. Acreditávamos que a prática que desenvolvíamos antes da entrada no Profletras era diferenciada porque sempre estimulamos respostas diferenciadas dos alunos, mas não olhávamos criticamente para o livro didático. Mesmo trabalhando com textos diversos, de outras fontes, recaíamos no mesmo de não elaborar questões mais relevantes que levassem o aluno para além do que estava posto no texto, proporcionando a ele a possibilidade de fazer relações, bem como questionar o próprio texto. A AD nos proporcionou essa compreensão.

A leitura na escola consiste, quase sempre, e a proposta em circulação nas políticas de ensino de Mato Grosso vem dizer dessa regularidade, em "saber extrair 
informações do texto" (INDURSKY, 2010, p. 164). Essa formulação faz sentido não só quando olhamos para os descritores da Prova Brasil, mas também quando nos recordamos de quantas vezes nossos alunos, mesmo sendo solicitado a eles uma leitura sem cobrança, iam em busca de respostas, no interior do texto, para as perguntas que elaborávamos ou apresentadas no material didático utilizado. Não refletiam sobre, não saboreavam o texto, seja literário ou não, apenas “caçavam” respostas, pois esta é uma prática que realizavam desde seus primeiros anos na escola. E, por recebermos esses alunos apenas a partir do sexto ano do Ensino Fundamental, parece-nos que esta prática é efeito de certa doutrinação e inculcação. Sobre essa questão, Hashiguti (2009, p. 27, grifos da autora) diz que "ler na escola ganha o sentido de repetir empírica ou formalmente, submetendo-se a respostas que sejam ilusões do resgate daquilo que o autor quereria dizer, e a escola, então, fica sendo uma prisão... de sentidos”.

Devido a seu funcionamento, a escola produz "o leitor da superfície dos sentidos literais”. (ROMÃO; PACÍFICO, 2006). A consequência é “a interdição à interpretação” e o impedimento ao aluno do diálogo "com o discurso do outro", o que acaba por lhe impor "um lugar de silenciamento" (ROMÃO, PACÍFICO, 2006, p. 80). Esse funcionamento se dá também por meio do professor, que, muitas das vezes, repete o discurso da Instituição. Atitudes essas que necessitam ser questionadas, transformadas, ressignificadas.

Orlandi (2012a, p. 7) afirma que a leitura, em sua acepção mais ampla, pode ser entendida como "atribuição de sentidos" e que, diante de um exemplar de linguagem, de qualquer natureza, tem-se a possibilidade da interpretação e que esta "deve ter, na escola, uma importante função no trabalho intelectual geral”. (ORLANDI, 2012a, p. 46). Ao trabalharmos a leitura, é imprescindível que se considerem alguns componentes das suas condições de produção, tais como:

os sujeitos (autor e leitor), a ideologia, os diferentes tipos de discurso, a distinção entre leitura parafrástica (que procura repetir o que o autor disse) e a polissêmica (que atribui múltiplos sentidos ao texto), assim como [...] a necessidade de se levar em conta as histórias de leitura do texto e as histórias de leitura do leitor (ORLANDI, 2012a, p. 49).

A autora ainda afirma "que o espaço de leitura escolar exclui da sua consideração o fato de que o aluno convive em seu cotidiano com diferentes formas de 
linguagem" (ORLANDI, 2012a, p. 50). A escola valoriza demasiadamente a leitura de textos verbais em detrimento de textos não verbais, como imagens, músicas, vídeos, entre outros. Além disso, há uma imagem de leitor construída pela escola. Orlandi (2012a, p. 51) ressalta que, "na definição desse aluno-leitor, já temos duas determinações negativas: exclui-se a sua relação com outras linguagens e exclui-se a sua prática de leitura não escolar”. Por essa razão, concordamos com a proposta de desenvolver uma

relação dialética entre aprendiz e professor na construção do objeto de conhecimento, no caso presente, a leitura. Assim como o aluno não está no grau zero, o professor não está no grau dez e a relação entre eles pode ser fecunda para ambos (ORLANDI, 2012a, p. 52).

O percurso deve ser construído por aluno e professor, mas, para essa relação acontecer, o professor precisa perceber-se sujeito capaz de observar, refletir, analisar e resistir às imposições que aparecem como naturalizadas no dia a dia de seu fazer docente, para que possa, apesar das relações de força em funcionamento no espaço escolar, promover um deslocamento das suas práticas e inserir os alunos nesse processo de ressignificação do ensino na sala de aula.

Na perspectiva discursiva com a qual nos identificamos, a finalidade do trabalho com a leitura é possibilitar aos alunos gestos de interpretação - atos no nível do simbólico, pois são práticas discursivas, linguísticas, históricas e ideológicas que interferem no real do sentido (ORLANDI, 2007) - que lhes têm sido negados, devido a toda uma conjuntura sócio-histórica na qual estamos inseridos:

$\mathrm{Na}$ escola, é aberta ao aluno a possibilidade de se colocar na função de 'submissão sem falhas', mas apenas aparentemente na 'vontade sem limites'. Ou seja, apesar de ser cobrado como capaz de controlar a linguagem - se quisesse - ele não tem espaços de interpretação abertos, portanto, não consegue se sentir dono do seu dizer: ele não entra, sequer, no efeito de linguagem que a forma sujeito atual apresenta. (PFEIFFER, 1995, p. 37, grifos da autora).

De certa forma, em nossa prática ao longo dos nove anos de trabalho, esperávamos muito dos nossos alunos sem lhes oferecer as condições mínimas, como acesso a um arquivo de leitura diversificado relativo a um tema trabalhado em sala de aula, por exemplo, para que ele se tornasse sujeito do que diz. E quando pensamos em 
autoria do sujeito-aluno, Pfeiffer (1995, p. 44) nos ensina: “o nosso sujeito-autor está vinculado ao sujeito de direito que tem responsabilidade sobre o que diz, mas ao mesmo tempo, tem o dever de dizer o esperado". Da forma como fazíamos, não nos dávamos conta de que o aluno não tinha direito à interpretação, era apenas repetidor do que era trazido até ele. Dessa maneira, não lhe eram permitidas outras possibilidades de interpretação. A escola, enquanto instituição, apresenta um discurso que legitima leituras autorizadas, como, por exemplo, a dos críticos, efeito das relações de poder na sociedade em funcionamento na escola. Como consequência, o aluno não tem voz. Mas não era nessa direção que queríamos trabalhar, e, por essa razão, fomos ao encontro dos alunos com os quais desenvolveríamos o Projeto para ouvir o que tinham a nos dizer, como condição para elaborarmos, efetivamente, a nossa Proposta de Intervenção.

\section{Do processo de se dar voz aos alunos}

No intuito de conhecer a turma com a qual trabalharíamos e de nos deslocarmos das antigas práticas de linguagem, promovemos três encontros durante o processo de construção do Projeto. O nosso primeiro contato teve a finalidade de conhecer os sentidos pré-estabelecidos pelos alunos sobre leitura e leitor. Construímos um roteiro de perguntas que norteou nossa conversa e esse primeiro momento deu-se apenas oralmente. Após longa discussão sobre as várias possibilidades de leitura que fazemos no nosso dia-a-dia, ao serem questionados sobre, apenas um quarto da turma se considerou leitor, o que diz do imaginário que os alunos têm sobre o que é ser leitor. Sentido que também circula entre os professores, quando, nos corredores e nas reuniões, se queixam de que os alunos não gostam de emprestar livros da biblioteca. Ao falarmos de imaginário, referimo-nos ao funcionamento do conceito de formações imaginárias (PÊCHEUX, [1969] 1997), através das quais o sujeito projeta imagens de si, do seu interlocutor e daquilo sobre o que fala.

Observamos que alunos e professores compartilham do sentido de que ser leitor é realizar a leitura de livros impressos, extensos, mas diferem na especificidade do 
livro: enquanto os professores, em grande parte, superestimam os clássicos literários, os alunos que se consideram leitores gostam dos livros que comparecem em listas mais recentes de best-sellers, tais como A culpa é das Estrelas, de John Green, Depois de Você, de Jojo Moyes, a saga Harry Potter e Animais Fantásticos e Onde Habitam, de J. K. Rowling, a saga Percy Jackson e os Olimpianos de Rick Rordan, livros que foram apontados pelos alunos que se consideraram leitores e não fazem parte do acervo da escola. Compareceu nessa discussão a voz dos alunos que não se consideram leitores, muito embora tenham dito que leem gibi ou alguma revista de divulgação científica, o que nos remete a sentidos pré-construídos, que funcionam, nesse imaginário, como critérios para caracterizar um sujeito como leitor.

Nunes (2003, p. 27) "distingue três instâncias ideológicas determinantes da leitura hoje: a instância do jurídico, a do econômico e a do político”. Observamos nossos alunos ligados a essa instância econômica, em que a quantidade de livros é fundamental para que se considerem leitores, já que é essa visão que a sociedade capitalista põe em circulação para estimular o consumo. Nesse sentido, o perfil do leitor da escola pública no Brasil tem se caracterizado, no mais das vezes, pelo educacional e pelas condições econômicas em vigor no país (NUNES, 2003).

Embora nosso foco neste trabalho não esteja direcionado para esse leitor brasileiro em geral, o imaginário do "bom" leitor reverbera nas discursividades que ouvimos, afinal, muitos dos nossos sujeitos-alunos se identificam com esse sentido imaginário.

Outro sentido produzido está no fato de os alunos, durante a conversa, concordarem e dizerem que "sabem" que a leitura está presente em todos os momentos de nossas vidas, dentro e fora da escola. Ainda assim, apontam para um perfil específico do que consideram um sujeito leitor. Entretanto, "não há uma forma de leitor, mas uma variedade de leitores e, além disso, o próprio leitor muda conforme as situações de linguagem" (ORLANDI, 2003, p. 23).

Com base nessa discussão, partimos para um momento de diálogo com os alunos em busca de sugestões para o desenvolvimento do nosso trabalho no semestre posterior. Ao serem questionados sobre os temas com os quais poderíamos trabalhar e sobre os textos com os quais os alunos se identificavam, foram sugeridos poemas, cartazes, entrevistas e texto dissertativo e as temáticas álcool, drogas e gravidez na 
adolescência emergiram. Finda a conversa, pedimos que os alunos fizessem um registro das preferências apontadas, em uma folha à parte que foi entregue a nós, o que aconteceu parcialmente, pois nem todos se dispuseram a materializar verbalmente suas preferências através do registro escrito. Esta situação nos remeteu a Pfeiffer (1995, p. 56):

O medo que percebemos nos alunos de terem de pegar no lápis e enfrentar a folha de papel em branco com inúmeras linhas a serem preenchidas, faz-nos perceber que para além da dificuldade imposta pela própria instituição escolar (de não permitir a textualização) talvez esteja funcionando uma memória histórica do texto como exposição do sujeito.

Vimos nesse momento um duplo desafio a ser enfrentado: a maneira como os alunos compreendiam o que é leitura e o que é ser leitor e, também, sua relação com a escrita na escola. A Instituição cumpria seu papel de homogeneizadora dos sentidos e dos sujeitos-alunos, que, assujeitados, reproduziam em suas formulações essa determinação.

No último contato com a turma antes do início do desenvolvimento do Projeto, ratificamos a escolha do tema "drogas" e descartamos "gravidez na adolescência", dada a necessidade de recorte, mas mantendo o desejo exposto pelos alunos, acolhendo suas sugestões. O tema "drogas" é um assunto constante na pequena cidade. É comum acontecer roubos e furtos a residências realizados por usuários, que acaba repercutindo na cidade toda, porque a maioria das pessoas se conhece e se sente igualmente afetada pelo problema, mesmo que não aconteça na sua casa. No entanto, a questão da violência foi somente um dos sentidos tomados neste trabalho, uma vez que outros sentidos sobre essa temática circularam, como aqueles filiados à saúde pública. Nesse sentido, compreendemos que nos abrir à escuta dos alunos para a concepção deste trabalho foi um deslocamento no modo de como a escola funciona, de forma a ressignificar o funcionamento da divisão social do trabalho da leitura (PÊCHEUX, 2010) nesta sala de aula.

Ao mesmo tempo, entendíamos a relevância de trabalharmos essa temática, por isso, recorremos aos Temas Transversais apresentados nos Parâmetros Curriculares Nacionais (PCNs, doravante) para justificar, na escola, se trabalhar com "questões 
importantes, urgentes e presentes sob várias formas na vida cotidiana” (BRASIL, 1998, p. 17). Além disso,

as questões biopsicossociais adquiriram maior visibilidade, e a escola foi compelida - pelas circunstâncias e pelo reclamo da própria sociedade - a lidar com problemas emergentes, como [...] o consumo abusivo do álcool e outras drogas, a violência social e as diferentes formas de preconceito. E não há como lidar com esses temas por meio da mera informação ou da prescrição de regras de comportamento (BRASIL, 1998, p. 262).

Segundo Zoppi-Fontana (2009), o professor de Língua Portuguesa pode contribuir com a discussão sobre temas de natureza transversal e mostrar que

a língua participa, através das práticas discursivas, na produção das atitudes, convicções, crenças, verdades e consensos que configuram nossas práticas sociais, direcionando nossa ação, nosso modo de estar no mundo e os vínculos e laços sociais que estabelecemos com os outros com os quais convivemos na sociedade (ZOPPI-FONTANA, 2009, p. 1, grifos da autora).

Considerando as condições de produção de leitura e escrita que a escola oferece, o desafio estava justamente em fazer nosso aluno refletir sobre sua posição e se sentir autorizado a mostrar seu posicionamento frente às questões que lhe serão postas, dando visibilidade a seus gestos de interpretação. Como bem nos ensina ZoppiFontana (2009, p. 8, grifos da autora):

São os gestos de interpretação que configuram tanto as práticas de escrita quanto as de leitura e compreensão de textos. [...] A interpretação é condição de possibilidade da leitura e da escrita: é pela sua relação com determinados sentidos já-ditos, presentes como interdiscurso, que o sujeito pode se constituir em autor do seu texto, assim como em leitor.

Com essas questões no horizonte de nosso processo de elaboração da proposta, definimos o objetivo geral do Projeto: trabalhar a leitura e a escrita pelo viés da Análise de Discurso, objetivando dar condições aos alunos de ressignificarem essas práticas, por meio de temas considerados polêmicos, como drogas "lícitas" e "ilícitas". Na sequência às conversas com os alunos, também definimos como objetivo específico: construir, com a participação dos alunos, um arquivo de leitura composto de diferentes materialidades sobre a temática selecionada e desestabilizar a evidência de sentido de leitura como prática voltada tão somente ao texto verbal, sobretudo literário, e, geralmente, longo. 
Pensando no encerramento do Projeto, redigimos o objetivo específico: desenvolver uma campanha de alerta ao uso de drogas com panfletagem na cidade, a fim de se colocar em evidência o processo de constituição da autoria. Por fim, pensando na circulação do Projeto, formulamos: elaborar uma página no Facebook para circular os trabalhos desenvolvidos ao longo do projeto e, assim, dar visibilidade a todo o processo.

Para dar novo sentido à prática de leitura e de escrita na escola é que pretendíamos, no início do desenvolvimento do Projeto, retomar os questionamentos que fizemos quando das visitas para desestabilizar o sentido de leitura que circula entre os nossos alunos, dando-lhes a oportunidade de desenvolver e elaborar seus gestos de interpretação, dando visibilidade a sua autoria, a partir da constituição de um arquivo sobre o tema pesquisado. Seria por meio desse arquivo, compreendido como um "campo de documentos pertinentes e disponíveis sobre uma questão" (PÊCHEUX, 2010, p. 57), que os alunos poderiam refletir sobre e relacionar os diversos discursos que circulam na sociedade acerca dos temas escolhidos. Daríamos condições para que os alunos percebessem a multiplicidade de sentidos que circulam na sociedade, em certas instituições, e até mesmo os sentidos que circulam como evidentes dentro e fora da escola e que poderiam ser ressignificados no decorrer desse Projeto.

Quanto à opção pela circulação das atividades em meio digital, a partir de uma página no Facebook, acreditávamos que essa prática se distanciaria do simulacro que a escola se utiliza comumente, ao solicitar textos para situações de "faz-de-conta", para fins somente avaliativos, e, assim, daríamos condições ao aluno de se apropriar da língua em funcionamento. Dessa maneira, almejávamos que o aluno pudesse se reconhecer como autor, assumindo essa função "enquanto produtor de linguagem" (ORLANDI, 2012a, p. 103).

O uso das tecnologias digitais funciona de maneira naturalizada para a geração que se encontra no Ensino Fundamental. Em relação ao uso das TICs em sala de aula, Dias (2011, p. 53) nos alerta que

o que temos feito, em geral, com o uso das tecnologias da informação e comunicação no contexto escolar, por exemplo, a fim de atender à demanda político-ideológica da inovação, é impor um discurso do novo sobre a memória do velho. Temos transportado um modo de fazer para outro sem dar 
lugar para a criatividade, para a interpretação, para a compreensão do processo e das implicações ideológicas desse fazer.

Pretendíamos utilizar a rede social como lugar de funcionamento da linguagem enquanto relação entre sujeitos na sociedade atual de modo a aproveitar a disponibilidade do recurso e a acessibilidade desses alunos que utilizam a rede no seu dia a dia, a fim de ressignificar seu uso na escola, onde costuma ser apenas instrumento no âmbito do utilitário (DIAS, 2011). Pensávamos que a criação de uma página na rede social Facebook referente ao projeto proporcionaria relações entre sujeitos usuários desta plataforma, a saber: nós, professores, nossos alunos (da turma), outros alunos, professores, amigos, vizinhos, conhecidos, entre outros. Os alunos não somente fariam postagens, mas também poderiam curtir, comentar, compartilhar e responder a comentários que surgissem.

Portanto, não queríamos utilizar as TICs somente para a digitação de um texto ou uma pesquisa, embora também sejam necessárias para esses trabalhos. Conforme De Conti et. al (2014, p. 63),

\begin{abstract}
as informações, já em ampla circulação pela web, não trazem as respostas prontas. Os textos (em suas mais diversas materialidades) precisam ser mobilizados, interpretados, colocados em confronto, debatidos. Aí se inserem os alunos - mobilizando esses textos, contrastando seus sentidos - e os professores - promovendo debates, questionamentos, delimitando os sentidos, articulando as diversas respostas mobilizadas pelos alunos. Constituindo, enfim, os objetos digitais em tecnologias de educação em sala de aula.
\end{abstract}

Desse modo, até a pesquisa poderia ser ressignificada, através desse outro olhar para os materiais coletados, a partir dos quais poderíamos funcionar como debatedoras de “interpretações possíveis diante as materialidades significantes”. (DE CONTI et. al, 2014, p. 63).

Por fim, pensando em nosso produto final ${ }^{8}$, a produção do panfleto para nossa campanha exigiria do aluno, após tantas leituras, assumir a autoria, "buscando controlar os sentidos do texto, percebendo a possibilidade do equívoco e encontrando 'brechas' para marcar sua identidade no discurso, dando 'roupagem nova', reformulando os sentidos que circulam (interdiscursos), considerando seu

\footnotetext{
${ }^{8}$ Institucionalizado por meio da Portaria Normativa $n^{\circ}$ 17, de 28 de dezembro de 2009 (CAPES).
} 
interlocutor" (RODRIGUES; PACÍFICO, 2007, p. 57). O aluno iria escrever não somente para o professor na sala de aula, mas para a comunidade escolar e também para a sociedade de Acorizal e, além dela, a outros leitores do Facebook, o que implicaria mais atenção e responsabilidade durante essa escrita. Conforme Orlandi (2012b, p. 9), a circulação do discurso "se dá em certa conjuntura e segundo certas condições" e os efeitos de sentido que podem surgir não são alheios à sua maneira de circular: "os 'meios' não são nunca neutros”. (ORLANDI, 2012b, p. 11).

Assim, tínhamos esses objetivos para serem alcançados e precisávamos ainda de mais embasamento teórico para pensarmos no desenvolvimento do Projeto propriamente dito.

\section{Da teoria à prática: quando os sentidos começam a fazer sentido}

Como efeito de um processo gradual de apropriação teórica, produzido pelas leituras em $\mathrm{AD}$, continuamos a refletir sobre o funcionamento da linguagem em sala de aula, pois "a linguagem permeia as relações entre alunos e professores, colocando sujeitos, história e ideologia em movimento durante o processo de ensinoaprendizagem” (FURLAN; MEGID, 2009, p. 9) e, ao mesmo tempo, fomos descobrindo novas possibilidades de conceber nosso trabalho como docente de língua portuguesa.

Para a $\mathrm{AD}$, o que interessa é "compreender a língua fazendo sentido, enquanto trabalho simbólico, parte do trabalho social geral, constitutivo do homem e da sua história" (ORLANDI, 2015, p. 13). A língua não é "asséptica, sem sujeito, sem atividade linguageira, sem exterioridade, sem sentido", e sim "uma língua que convoca sujeitos historicamente determinados, inscritos em lugares sociais, a partir dos quais enunciam seu discurso" (INDURSKY, 2010, p. 170). Esse entendimento de língua distancia-se do sentido que filiava nosso trabalho em sala de aula antes de ingressarmos no Profletras: uma língua transparente, de sentido único e “dominável”.

Como nos lembra Indursky (2010, p. 169), “a AD não tem por tarefa descrever a língua, mas analisar discursos, processos discursivos, processos de significação”. É por essa razão que, no horizonte de um trabalho que visa a novas práticas de leitura e 
escrita na escola, recorremos a essa teoria, a fim de nos deslocarmos de práticas legitimadas ao longo da história e instaurar um novo movimento no trabalho de ensino de língua nas aulas de Língua Portuguesa.

Em todas as relações sociais, por meio da linguagem, podemos observar relações de força que são reforçadas e legitimadas ao longo do tempo. E, para a $\mathrm{AD}$, essas relações também são fundamentais para a compreensão dos efeitos de sentido que se realizam no sujeito em determinado momento sócio-histórico. Como nos propusemos a ressignificar a prática de leitura e escrita na escola, precisávamos também entender um pouco do funcionamento da escola em nossa sociedade, a escola enquanto Instituição. Ao longo de sua existência, as Instituições produzem práticas que, aos poucos, vão se naturalizando, ou seja, passamos a vê-las como naturais e que determinam os discursos dos sujeitos que a elas se filiam (FURLAN; MEGID, 2009).

Dessa maneira, a escola institucionaliza os papéis para professor e aluno, aquele com autorização para legitimar o saber e este com autorização para reproduzir este saber, o que significa que há determinadas práticas permitidas a uns e não a outros. Seja na posição-professor, seja na posição-aluno, essas posições-sujeitos estão inscritas na conjuntura sócio-histórica ideológica na qual nos inserimos. E, pelo efeito ideológico, sem percebê-las, estamos envoltos pelo seu funcionamento.

Em consonância com a $\mathrm{AD}$, a escola é regida por um discurso próprio: o Discurso Pedagógico, que pode ser caracterizado, segundo Orlandi (2011, p. 15, grifos da autora), "como um discurso autoritário", por meio do qual compreendemos que há um trabalho de administração de sentidos estabelecidos pela ideologia capitalista. Na sala de aula, como efeito, o sentido que prevalece é o estabelecido pelo professor ou até mesmo pelo livro didático. O que mais surpreende nessa concepção de discurso pedagógico em funcionamento na escola é que essa compreensão foi formulada por Orlandi durante a Ditadura Militar no Brasil e, décadas depois, vem sendo atualizado, produzindo efeitos avassaladores.

Dessa maneira, o discurso pedagógico em funcionamento na escola tende ao discurso autoritário, que está relacionado, por exemplo, ao ensino de língua com sentido único e transparente e os alunos tornam-se repetidores de respostas prontas, sem possibilidade de deslocamentos. 
A instituição escolar produz um discurso que muitas vezes só percebemos ao nos colocarmos de fora do processo. Aprender/estudar a AD tem nos permitido observar e refletir sobre o funcionamento da escola e das relações que se dão entre os sujeitos no funcionamento dessa Instituição. Ao pensarmos em uma ressignificação para o trabalho em sala de aula e "especificamente, em relação ao DP, uma forma não autoritária é explicitar o jogo dos efeitos de sentido em relação a informações colocadas nos textos e dadas pelo contexto histórico-social” (ORLANDI, 2011, p. 32). Com essa proposta e desejo que buscamos trabalhar com nossos alunos.

Amparadas nos conceitos da $\mathrm{AD}$, propusemos um modo de trabalho que se distancia do que tem sido realizado na escola. Não podemos ficar inertes diante de práticas em que professor e alunos são engessados, mesmo que haja relações de força que tentam determinar as práticas escolares em uma sociedade capitalista como a nossa. Por essa razão, concordamos com Orlandi (2011, p. 35, grifos da autora), quando diz que

enquanto professores, não estamos excluídos desse dizer-ato-decisão quando se trata do trabalho pedagógico. Trata-se então, em relação ao discurso educacional, de atuarmos criticamente, nas duas direções, em relação aos que nos cristalizam (os que se pronunciam sobre a educação) e aos que nós, reprodutoramente, cristalizamos (em nosso trabalho de educação).

Com o intuito de fazermos algo que fosse ao encontro da formação de nossos sujeitos-alunos, produtores de sentidos, que se distanciasse de um discurso pedagógico autoritário, é que nos identificamos com os conceitos de leitura, gestos de interpretação e autoria sustentados na AD.

Segundo Orlandi (2012a, p. 114), “a leitura é produzida em condições determinadas, ou seja, em um contexto sócio-histórico que deve ser levado em conta”. Há processos complexos em torno da leitura, desde o contexto estrito (quem falou, para quem, onde, quando) até o contexto amplo (conjuntura sócio-histórica). Os dizeres formulados no intradiscurso relacionam-se com os dizeres possíveis no universo de já-ditos em circulação no interdiscurso e os efeitos de sentido podem ser tantos quantos se fizerem possíveis, em determinadas condições de produção.

Queríamos considerar, no trabalho em sala de aula, que "todo leitor tem sua história de leitura. O conjunto de leituras feitas configuram, em parte, a 
compreensibilidade de cada leitor específico" (ORLANDI, 2012a, p. 57). O diálogo com os alunos é fundamental para que saibamos das experiências de leituras dos nossos alunos e, a partir delas, façamos o planejamento do nosso trabalho. A ausência dessa prática culmina no autoritarismo do professor, que vai considerar um "absurdo" o aluno não compreender determinado texto, enquanto o aluno não encontrará razão alguma para ler algo que lhe é indiferente. Outra consequência da ausência dessa abertura é a possibilidade de o aluno não estabelecer relações entre textos, necessárias para o movimento do sentido, em determinadas condições de produção. Um deslocamento nessas práticas é possível. Como nos orienta Orlandi (2012a, p. 59), “o professor pode modificar as condições de produção da leitura do aluno: de um lado, proporcionando-lhe que construa sua história de leituras; de outro, estabelecendo, quando necessário, as relações intertextuais, resgatando a história dos sentidos do texto".

A leitura e interpretação para a AD caminham juntas. Interpretar é algo que fazemos desde a mais tenra idade, assim que nos tornamos sujeitos interpelados pela ideologia. Orlandi (2007, p. 64) afirma que "a interpretação é uma injunção. Face a qualquer objeto simbólico, o sujeito se encontra na necessidade de ‘dar' sentido”. Além disso, interpretar também está relacionado ao silêncio e ao não-dito. Se dizer significa, não dizer significa igualmente. $\mathrm{O}$ aluno não aprende a interpretar na escola, pois já faz esse gesto durante toda sua vida, mas podemos e devemos criar condições de desenvolvimento desse trabalho com a leitura de textos a partir da constituição de um arquivo de leitura elaborado pelos alunos. Para a autora,

\footnotetext{
a interpretação, portanto, não é mero gesto de decodificação, de apreensão do sentido. Também não é livre de determinações. Ela não pode ser qualquer uma e não é igualmente distribuída na formação social. O que a garante é a memória sob dois aspectos: a) a memória institucionalizada, ou seja, o arquivo, o trabalho social da interpretação em que se distingue quem tem e quem não tem direito a ela; e b) a memória constitutiva, ou seja, o interdiscurso, o trabalho histórico da constituição da interpretação (o dizível, o repetível, o saber discursivo) (ORLANDI, 2007, p. 67-68).
}

A leitura e os gestos de interpretação vão ao encontro do processo de assunção da autoria, pois o aluno, para assumir a posição-autor, historicizando seu dizer, deverá ter o que dizer. Pela perspectiva discursiva, a escola poderia promover esta prática 
sustentada no trabalho com a historicidade. Sobre a autoria, Pfeiffer (1995, p. 76) nos esclarece que

para que o sujeito se coloque na posição de autor é preciso que ele crie um espaço de interpretação (a possibilidade do gesto interpretativo que vem do outro - virtual). Ao mesmo tempo, ele precisa necessariamente estar em relação (inserido no) com o Outro - o interdiscurso.

Todo autor projeta um leitor virtual, seu interlocutor em potencial. Essa relação é determinante para a produção textual, bem como a relação com o interdiscurso, pois a interpretação só é possível quando há uma relação com os sentidos produzidos historicamente: “a autoria na escola está [...] no limiar da repetição formal com a repetição histórica" (PFEIFFER, 1995, p. 91). O aluno não se torna autor com a mera repetição de frases prontas, lidas ou ouvidas durante a aula. Ele precisa se representar na origem do seu dizer. Nesse processo, entra a escola com a responsabilidade de promover práticas que levem o aluno a se tornar efetivamente autor.

Gallo (1990, p. 25, grifo da autora), ao falar do processo de assunção da autoria, nos lembra que

a única garantia que podemos ter como professores de língua portuguesa, é a de propiciar condições para que nossos alunos possam se inscrever em posições-sujeito de discursos onde o efeito AUTOR é possível, ou seja, em outros discursos que não sejam somente circulares e auto-avaliativos, como é o caso do discurso didático-pedagógico.

Construto das suas condições sócio-históricas e ideológicas, a escola, muitas vezes, ainda apresenta dificuldades em proporcionar essa assunção da autoria ao aluno, como vimos acontecer nas propostas de trabalho voltadas à Prova Brasil. Gallo (1990, p. 67, grifo da autora) nos lembra que a "textualização pode ser uma prática da escola porque as determinações do discurso pedagógico não são as únicas determinantes do sujeito aí inscrito". Mesmo a escola não sendo uma instituição produtora, mas sim conservadora e mantenedora do discurso escrito, é possível, por meio de práticas que visem a uma "utilidade" para os textos, promover o desenvolvimento da autoria nos alunos. Esse processo de textualização, "em resumo [...] é a prática de produção de texto" (GALLO, 1990, p. 194). 
Como nos esclarece a autora, essa prática "só é efetivada nos casos onde houver um momento de fechamento, de conclusão [...] necessariamente fora (da Escola e) do discurso didático-pedagógico" (GALLO, 1990, p. 118).

Sustentadas pela reflexão sobre o funcionamento da escola e das posiçõessujeito aluno e professor, reforçadas ao longo do tempo e embasadas nos conceitos da $\mathrm{AD}$, que pretendíamos desenvolver neste Projeto, a fim de promover um deslocamento das práticas até então postas em funcionamento por nós e, assim, também deslocar nossos alunos das posições em que se encontravam, partimos para o momento de estruturar, a partir dos objetivos geral e específico estabelecidos/definidos, a metodologia de desenvolvimento da proposta de intervenção.

\section{A teoria materializada na prática: procedimentos metodológicos}

No intuito de nos distanciarmos da maneira como se realiza o discurso pedagógico na escola, a metodologia deste Projeto, sustentada fortemente na teoria, se pautou em trabalhar em diálogo constante com os alunos da turma escolhida. Porém, em caráter de organização e planejamento, propusemos três fases para o trabalho de intervenção.

A primeira fase foi dedicada à construção de um arquivo de leitura composto de diferentes materialidades significantes (ORLANDI, 2002), de modo a propiciar discussões e o estabelecimento de relações entre as informações encontradas. Nesse sentido, nos apoiamos em Romão e Pacífico (2006, p. 50): "o espaço da sala de aula precisa ser inundado por diversos portadores de texto, de diferentes materialidades, que possam remeter o aluno a um lugar povoado por várias vozes, em que os sentidos sejam plurais”. Também consideramos, como nos sugerem Bolognini e Lagazzi (2009, p. 4, grifos das autoras), que

as mais diferentes materialidades da linguagem - configuradas como textos escritos, fala, músicas, desenhos, pinturas - são exemplos de objetos simbólicos, por serem formados por símbolos, sejam eles gráficos, sejam eles sonoros. Essas materialidades estão expostas ao trabalho do simbólico, se constituindo em objetos simbólicos para o sujeito. Esses objetos simbólicos 
estão na dimensão do discurso, o que significa que o trabalho do simbólico é sempre determinado pelas condições de produção do discurso e se faz, como já afirmamos acima, enquanto produção de efeitos de sentido entre locutores.

Nesse processo, seria possível trabalhar com livros impressos do acervo da biblioteca da escola, bem como com materiais disponíveis na internet de diferentes materialidades significantes, como reportagens, dados estatísticos, campanhas, vídeos, charges, tiras, música, filme, gibis, propagandas e cartazes, levando em conta sua forma material (ORLANDI, 2015), pois estávamos certas de que "apenas o acesso ao arquivo, ou seja, somente o confronto e o contato com vários documentos relativos a uma questão podem dar ao aluno a possibilidade de se instalar na posição de autor" (ROMÃO; PACÍFICO, 2006, p. 88).

Considerando que "há gestos de leitura que constroem o arquivo" (ORLANDI, 2012b, p. 59), seria possível, na pesquisa e na seleção dos documentos, em um trabalho simultâneo de leitura e construção do nosso arquivo, colocar em evidência a opacidade e a equivocidade desses materiais, pois "os sentidos não são indiferentes à matéria significante, a relação do homem com os sentidos se exerce em diferentes materialidades, em processos de significação diversos: pintura, imagem, música, escultura, escrita, etc." (ORLANDI, 2007, p. 12).

A segunda fase foi pensada em proporcionar conversar com profissionais de diferentes instituições e áreas do conhecimento, como uma psicóloga, uma assistente social, uma enfermeira e um sociólogo. Entendemos que a exposição a vários discursos contribui para o processo de constituição da autoria, bem como para se produzir um deslocamento do que se realiza normalmente em sala de aula, sustentado na tríade aluno, professor e livro didático, mas também para se criar uma oportunidade para os alunos se expressarem e elaborarem questionamentos a esses profissionais que lidam cotidianamente com essas questões, pois, conforme Romão e Pacífico (2006, p. 61), "somente a leitura de várias vozes e a observação de que os sentidos são plurais e incontroláveis podem dialogar com o conceito de autoria”.

Também foram previstas entrevistas elaboradas em duplas, grupos e/ou coletivamente, sob nossa orientação, com alguns membros da escola, tais como alunos de anos variados e pessoas da comunidade, como familiares e vizinhos dos alunos, o que exigiria dos alunos, nesse processo, um responsabilizar-se pelo dizer (ORLANDI, 
2012a), iniciando pela definição da forma de registro, por escrito, em áudio ou vídeo, com base no roteiro construído, chegando à socialização, por meio de roda de conversa na turma.

A terceira fase foi pensada à elaboração/construção do efeito de fecho do Projeto. A proposta era a de que, com base na discussão das leituras constitutivas do arquivo, os alunos preparariam seminários de curta duração para serem apresentados na própria turma e em outras turmas da escola.

Também pensando no fecho, para a elaboração da campanha, definimos pela formulação, a constituição e a circulação dos panfletos. A escolha do panfleto se deveu ao fato de ser um tipo de texto comum no meio em que vivemos; produzir, em sua formulação, efeitos de objetividade e concisão, e, no que tange à circulação, favorecer tanto a do meio digital, quanto a do meio impresso - de mão em mão - em uma pequena cidade como a nossa. Pretendíamos que todos os panfletos produzidos circulassem também em meio digital, através da página de Facebook, pois entendemos, com Dias (2014, p. 12), que "a conectividade é um elemento do laço social contemporâneo e dos processos de identificação dos sujeitos”.

Nesse momento de finalização do Projeto, vislumbramos a participação dos alunos no processo de socialização dos trabalhos para a escola e a comunidade, pois pretendíamos, ao final do Projeto, fazer com que os alunos se inscrevessem na posiçãoautor e "essa assunção implica [...] uma inserção (construção) do sujeito na cultura, uma posição dele no contexto histórico-social” (ORLANDI, 2012a, p. 106), de forma que se sentissem autorizados a tomar a palavra, pois "os alunos não repetem aquilo que não lhes faz sentido, mas aprendem a partir do que eles já sabem, e constituem-se autores” (FEDATTO; MACHADO, 2007, p. 14).

Consideramos importante ressaltar que embora tenhamos concebido o Projeto filiado à Análise de Discurso e a escola tenha apoiado a nossa decisão, também foi preciso levar em conta, durante a intervenção, o estabelecido pelo Estado no que diz respeito à forma de avaliação da disciplina que ministramos. A partir dessa injunção, durante o desenvolvimento do projeto, por dois bimestres letivos, fomos responsabilizadas pelos lançamentos das avaliações dos objetivos de aprendizagem no sistema oficial, apesar de sustentarmos, explicitamente, uma proposta do trabalho ancorada em uma língua significada como opaca, não transparente, distanciada de 
uma concepção de língua supostamente clara e objetiva, imaginariamente materializada em alguns objetivos de aprendizagem na avaliação (im)posta pelo Estado, dada a relação de forças em funcionamento no espaço escolar.

De toda forma, o que propusemos e realizamos em sala de aula escapou às injunções institucionais e instauramos uma relação outra com o trabalho com a leitura e a escrita, efeito de um processo de autorização e legitimação que nos impulsionou a ousar nos revoltar e pensar por nós mesmas (PÊCHEUX, 2009).

\section{Considerações finais}

Partindo da compreensão de que mudanças no sistema de ensino são atravessadas "por questões políticas, administrativas, econômicas e, enfim, ideológicas” (PFEIFFER, 2003, p. 104) e a angústia solitária do professor não é frutífera, mas, enquanto docente, é impossível ser indiferente a essas questões, optamos por não cair “no discurso do Estado falido, descontrolado e portanto no 'sem-jeitismo”" (PFEIFFER, 2003, p. 104), ousando nos movimentar nesse espaço tensionado e produzir um outro sentido para a autoria na escola. Ler, refletir e discutir sobre as nossas condições de produção enquanto docentes no Brasil, em nosso caso, em Mato Grosso, são caminhos para compreendermos o funcionamento ideológico que nos atravessa e rompermos com o estabelecido. Em outras palavras, acreditamos que, para que possamos intervir em nossas práticas escolares, faz-se necessário primeiramente compreender o seu funcionamento.

Para finalizar, gostaríamos ainda de dizer que esta pesquisa não somente proporcionou um sentido de que os alunos têm autoridade a dizer, pois lhes foram dadas as condições a dizer, a escrever e se responsabilizar por suas práticas linguageiras inscritas na língua e na história. Ter construído esse processo produziu em nós a força necessária para "agir, refletir, elaborar", não nos "apagando sob a voz de uma ciência de cunho acadêmico que se coloca como a que tem o direito à interpretação” (PFEIFFER, 2003, p. 104). O primeiro passo dessa nova jornada foi dado. 


\section{Referências}

BOLOGNINI, Carmen Zink; LAGAZZI, Suzy. Provérbios. Quem ri seus males espanta. Projeto Conexão Linguagem. Unicamp, 2009. Disponível: <http://objetoseducacionais2.mec.gov.br/mec/16823>. Acesso em: 25 fev. 2016.

BRASIL. Resolução no o01/2014 - Conselho Gestor, de 23 de abril de 2014. Estabelece diretrizes para a pesquisa do trabalho final no Mestrado Profissional em Letras - PROFLETRAS. Disponível em: <http://www.profletras.ufrn.br/documentos/1934887 o7\#.W1JYNPZFzmI>. Acesso em: o1 jul. 2018.

BRASIL. Portaria no 17 CAPES, de 28 de dezembro de 2009. Dispõe sobre o mestrado profissional no âmbito da Fundação Coordenação de Aperfeiçoamento de Pessoal de Nível Superior - CAPES. Diário Oficial da União, Brasília, DF, n. 248, 29 dez. 2009. Seção 1, p. 20. Disponível em: <https:// www.capes.gov.br /images/download/legislaca/PortariaNormativa_17MP.pdf.> Acesso em: o1 jul. 2018. BRASIL. Parâmetros curriculares nacionais: terceiro e quarto ciclos do ensino fundamental: apresentação dos temas transversais. Brasília: MEC/SEF, 1998.436p. DE CONTI, Davi Faria; MEGID, Cristiane Maria; FURLAN, Cássia Cristina; MENSATO, Joice. O digital na escola: objeto, instrumento e tecnologia. In: BOLOGNINI, Carmen Zink. (Org.). A língua portuguesa: novas tecnologias em sala de aula. Campinas, SP: Mercado de Letras, 2014. p. 53-64. (Série Discurso e Ensino).

DIAS, Cristiane Pereira. O discurso da “inovação” no processo de significação de “mudança” na sociedade da informação. In: ZATTAR, Neuza; DALLA PRIA, Albano; MORALIS, Edileusa Gimenes (Orgs.). Linguagem, acontecimento, discurso. Cáceres, MT: Campinas, SP: RG, 2011. p. 45-6o.

ESCOLA ESTADUAL PIO MACHADO. Projeto Político Pedagógico (PPP). Acorizal, 2017. Documento interno da escola.

FEDATTO, Carolina Padilha; MACHADO, Carolina de Paula. O muro, o pátio e o coral ou os sentidos no/do professor. In: BOLOGNINI, Carmen Zink. (Org.). Discurso e ensino: o cinema na escola. Campinas, SP: Mercado de Letras, 2007. p. 9-16. (Coleção Discurso e Ensino). 
FURLAN, Cássia Cristina; MEGID, Cristiane Maria. Língua e linguagem em movimento na sala de aula. In: BOLOGNINI, Carmem Zink; PFEIFFER, Claudia; LAGAZZI, Suzy. (Orgs.) Práticas de linguagem na escola. Campinas, SP: Mercado das Letras, 2009. p. 918. (Série Discurso e Ensino).

GALLO, Solange Leda. Como apre(e)nder essa matéria? 1990. 214f. Tese (Doutorado em Linguística) - Instituto de Estudos da Linguagem, Universidade Estadual de Campinas, Campinas, 1990.

HASHIGUTI, Simone T. Nas teias da leitura. In: BOLOGNINI, Carmen Zink; PFEIFFER, Claudia; LAGAZZI, Suzy. (Orgs.) Práticas de linguagem na escola. Campinas, SP: Mercado das Letras, 2009. p.10-30. (Série Discurso e Ensino).

INDURSKY, Freda. Estudos da linguagem: a leitura sob diferentes olhares teóricos. In: TFOUNI, Leda Verdiani (Org.). Letramento, escrita e leitura: questões contemporâneas. Campinas, SP: Mercado das Letras, 2010. p. 163-178.

MATO GROSSO. Portaria n 161/2016/GS/SEDUC/MT, de 12 de abril 2016. Institui o Projeto de Estudos e Intervenção Pedagógica (PEIP), o Projeto de Formação Contínua dos Profissionais Técnicos e Apoio Administrativos Educacionais (PROFTAAE) e dá outras orientações. Diário Oficial do Estado de Mato Grosso, Ano CXXV, Cuiabá, MT, n. 26758, 14 abr. 2016. Disponível em: <file:///C:/Users/loja/Downloads/diario_oficial_2016-04-14_completo\%2o(1).pdf>. Acesso em: 23 jan. 2017.

. Orientações curriculares: área de linguagens: educação básica. Cuiabá, MT: Defanti, 2010a.

. Política de formação dos profissionais da educação básica de Mato Grosso. Cuiabá, MT: SEDUC, 2o1ob.

NUNES, José Horta. Aspectos da forma histórica do leitor brasileiro na atualidade. In: ORLANDI, Eni Puccinelli. (Org.). A leitura e os leitores. 2. ed. Campinas: Pontes, 2003. p. $25-46$.

ORLANDI, Eni. Puccinelli. Análise de discurso: princípios e procedimentos. 12. ed. Campinas, SP: Pontes, 2015. . Discurso e leitura. 9. ed. São Paulo: Cortez, $2012 a$. Discurso e texto: formulação e circulação dos sentidos. 4. ed. Campinas, SP: Pontes, 2012b. 
A linguagem e seu funcionamento: as formas do discurso. 6. ed. Campinas, SP: Pontes, 2011.

Interpretação: autoria, leitura e efeitos do trabalho simbólico. 5. ed. Campinas, SP: Pontes, 2007.

. Cidades dos sentidos. Campinas, SP: Pontes, 2004. Introdução: a leitura proposta e os leitores possíveis. In: (Org.). A leitura e os leitores. 2. ed. Campinas, SP: Pontes, 2003 p.7-24. . Língua e conhecimento linguístico. Campinas: Pontes, 2002. PÊCHEUX, Michel. Ler o arquivo hoje. In: ORLANDI, Eni P. (Org.). Gestos de leitura: da história no discurso. Tradução de Maria das Graças Lopes Morin do Amaral. Campinas: Editora da Unicamp, 2010. p.49-59.

. Semântica e discurso. 4. ed. Campinas: Editora da UNICAMP, 2009. . (1969). Análise automática do discurso (AAD 69). In: GADET, Françoise; HAK, Tony. (Org). Por uma análise automática do discurso: uma introdução à obra de Michel Pêcheux. 3. ed. Campinas, SP: Editora da Unicamp, 1997. p. 61-161.

PFEIFFER, Claudia Castellanos. O leitor no contexto escolar. In: ORLANDI, Eni Puccinelli. (Org.). A leitura e os leitores. 2. ed. Campinas: Pontes, 2003. p. 87-104. . Sentido para sujeito e línguas nacionais. Língua e Instrumentos Linguísticos, Campinas, n.7, p. 71-93, 2002.

. Que autor é este? 1995. 146f. Dissertação (Mestrado em Linguística) - Instituto de Estudos da Linguagem, Universidade de Campinas, Campinas, 1995.

RODRIGUES, Elídia de Souza Silva; PACÍFICO, Soraya Maria Romano. Investigações sobre autoria em textos produzidos por alunos de $4^{\underline{a}}$ série do Ensino Fundamental. In: ROMÃO, Lucília Maria Sousa; PACÍfICO, Soraya Maria Romano (Org.). Leitura e escrita: no caminho das linguagens. Ribeirão Preto, SP: Alphabeto, 2007. cap. 3. p.4977 .

ROMÃO, Lucília Maria Sousa; PACÍFICO, Soraya Maria Romano. Era uma vez outra história: leitura e interpretação na sala de aula. São Paulo: DCL, 2006.

SANTOS, M. J. dos. Gestos de interpretação e constituição da autoria: uma proposta de trabalho com o discurso sobre drogas "lícitas” e “ilícitas” no Ensino Fundamental. 2018. 225f. Dissertação (Mestrado em Letras) - Programa de Pós-Graduação Mestrado 
Profissional em Letras - PROFLETRAS, Universidade do Estado de Mato Grosso, Cáceres, 2018.

ZOPPI-FONTANA, Mônica. Combatendo o preconceito: argumentação e linguagem. Hora de debate. Campanhas de prevenção contra DST: linguagem em alerta. Projeto Conexão Linguagem. Unicamp, 2009. Disponível: <http://objetose ducacionais2.mec.gov.br/bitstream/handle/mec/16892/Guia\%2oMULHR-2-Soft-novo s\%20(1).pdf?sequence=3>. Acesso em: 22 nov. 2016.

Recebido em 25/07/2018.

Aprovado em 11/10/2018. 